\title{
An experimental study on relationship between hammett substituent constant and electronic absorption wavelength of some azo dyes
}

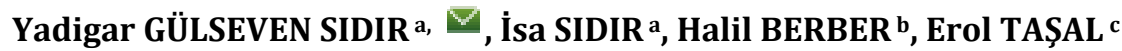 \\ a Bitlis Eren University, Faculty of Arts and Science, Department of Physics, 13000, Bitlis, Turkey \\ ${ }^{b}$ Anadolu University, Faculty of Science, Department of Chemistry, 26470, Eskişehir, Turkey \\ c Eskişehir Osmangazi University, Facuty of Arts and Science, Department of Physics, 26480, Eskişehir, Turkey \\ $\checkmark$ Corresponding author: Tel.:+904342285170; fax: +904342285171, E-mail address: ygsidir@bitliseren.edu.tr
}

\begin{abstract}
In this study, absorption spectra of sixteen azo dyes have been recorded in various solvents. These azo dyes have substituents such as $\mathrm{OH}, \mathrm{SO}_{3} \mathrm{H}, \mathrm{Cl}, \mathrm{I}, \mathrm{NO}_{2}, \mathrm{C}_{2} \mathrm{H}_{5}$ and $\mathrm{OCH}_{3}$ in different positions of phenyl ring. There is a shift in $\lambda_{\max }$ whose amount is dependent upon the type and position of substituent on the ring. The effects of substituent on the absorption spectra of azo dyes are interpreted by correlation of absorption maximum wavelengths $(\mathrm{nm})$ with the hammett substituent parameters. Charge transfer transitions are observed in inverse direction for azo dyes with electron acceptor substituent compared to azo dyes with electron donor.
\end{abstract}

Keyword: Absorption spectra, azo dye, electronic charge transfer hammett substituent constant, nonlinear optic

\section{Introduction}

Azo dyes are used in different industrial fields such as printing, electronic photography, color formers, liquid crystal display, laser technology, data storage, optical actuators, photorefractive media, fiber dye, food and cosmetics industry (Matsu et al. 1970; Gibson et al. 1991; Bartkiewicz et al. 2001; Gimenez et al. 2005; So et al. 2006; Qian et al. 2007; Qui et al. 2007).

Application of azo dyes to high technology has been attracting much attention in recent years (Gregory 1991) It has also been demonstrated that azo dyes substituted with donor-acceptor terminal groups have many features as non-linear optical (NLO) materials. Moreover, the presence of donor and acceptor moieties in azo dyes can be interested in the study of solvatochromism (Masoud et al. 2005).

The development of correlation between UV-Vis absorption and Hammett substituent constants is one of the major achievements of physical chemistry (Hansch et al. 1991). Hammett substituent coefficients $(\sigma)$ are used to evaluate the effect of the substituents upon the rate of a chemical reaction for which mechanism is known. Several studies were reported the correlation between UV absorption frequencies with substituent parameters (Issa et al. 1972; Kobayashi et al. 1987; Valentic et al. 1999; Ušćumlić et al. 2004; Mijin et al. 2006).

In our previous works, absorption spectra of azo dyes in different solvents were examined with linear solvation energy relationship using refractive index functions, dielectric functions and Kamlet-Taft parameters (Issa et al. 1972; Gülseven et al. 2009; Sıdır et al. 2009; Gülseven Sidır et al. 2011ab). In this present work, ultraviolet absorption spectra of 16 azo dyes have been recorded in the region of 200-600 $\mathrm{nm}$ in different solvents. Moreover, the substituent effect of sixteen azo dyes has been researched to correlate between $\pi-\pi^{*}$ electronic transition bands wavelengths with Hammett substituent constants.

\section{Experimental Section}

All of the investigated azo dyes were synthesized and purified using a previously reported method (Ermis 2003; Aksu 2007; Yıldırım 2007). Molecular structures of researched azo dyes was shown in Table 1.

The DMSO, DMF, EtOH, THF, benzene, $\mathrm{CCl}_{4}, 1,4$ dioxane, cyclohexane organic solvents were used for spectroscopic measurements and were graded analytically by Sigma \& Aldrich company. Each solution was prepared as about 2.10-5 M. All UV-vis spectra were acquired using Shimadzu UV-2550 spectrophotometer in standard $1 \mathrm{~cm}$ path length quartz cell at room temperature for spectral analysis.

In each recording, the instrument was reset with the solvent before the spectra of the dyes were acquired. Sample recording was done from $200 \mathrm{~nm}$ to $600 \mathrm{~nm}$. 
Table 1. Molecular structure of investigated azo dyes.

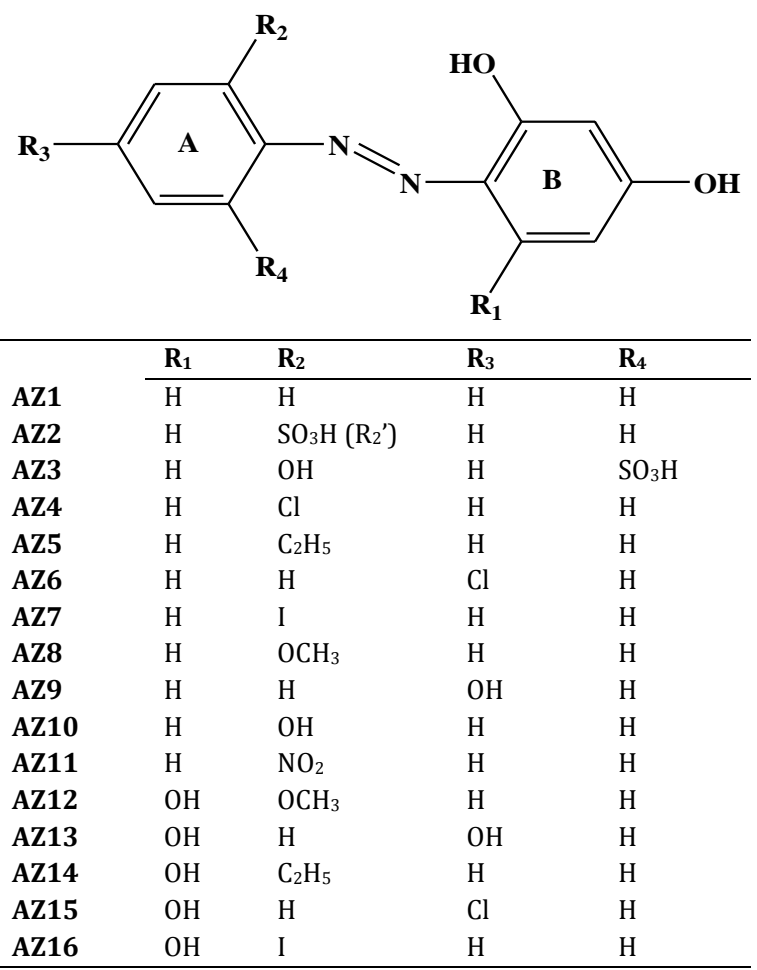

\section{Results and Discussion}

The characteristic absorption spectra of azo dyes recorded in DMSO, DMF, ethanol, THF, benzene, $\mathrm{CCl}_{4}$ and 1,4-dioxane are listed in Table 2 . As expected in non-polar solvents benzene and $\mathrm{CCl}_{4}$, azo dyes show three electronic absorption bands. These bands are due to the conjugation between the azo bridge and aromatic rings, the lone-pair located on the azo bridge and hydroxyl $(\mathrm{OH})$ groups and intramolecular $\mathrm{O}-\mathrm{H} . . . \mathrm{N}$ hydrogen bond formation, respectively (Issa et al. 1972; Gülseven et al. 2009; Sıdır et al. 2009; Gülseven et al. 2011a; Gülseven et al. 2011b). According to Table 2, the induction of electrons in substituents $\left(\mathrm{OH}, \mathrm{OCH}_{3}, \mathrm{C}_{2} \mathrm{H}_{5}\right)$ of benzene ring produce

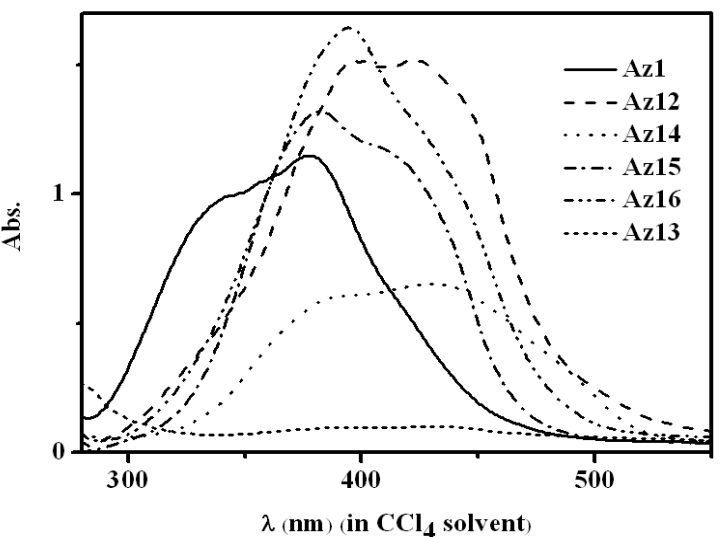

Figure 1. UV-Vis. spectra of investigated some azo dyes in the $\mathrm{CCl}_{4}$ solvent.

bathochromic shifts on the band wavelength absorption maximum as compared to that of Az1 in solvents. On the contrary, the shift in maximum absorption wavelength does not depend on electron acceptor substituents in benzene rings (Issa et al. 1972; Kobayashi et al. 1987; Valentic et al. 1999; Ušćumlić et al. 2004; Mijin et al. 2006)

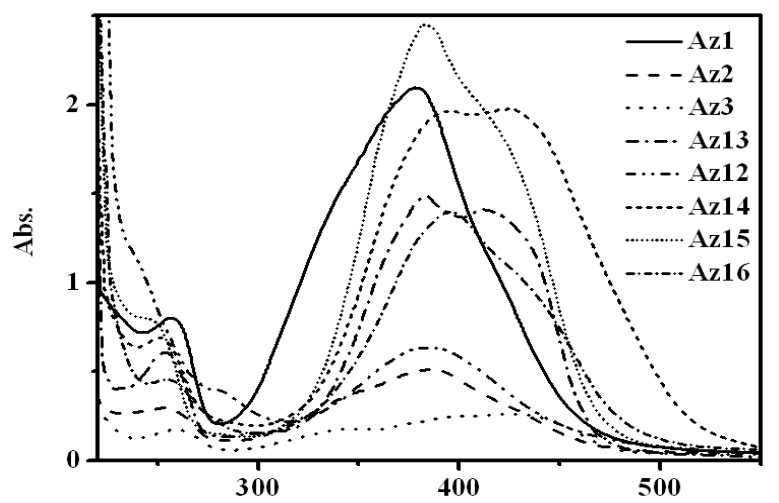

$\lambda$ (nm) (in 1,4-Dioxane solvent)

Figure 2. UV-Vis. spectra of investigated some azo dyes in the 1,4-Dioxane solvent

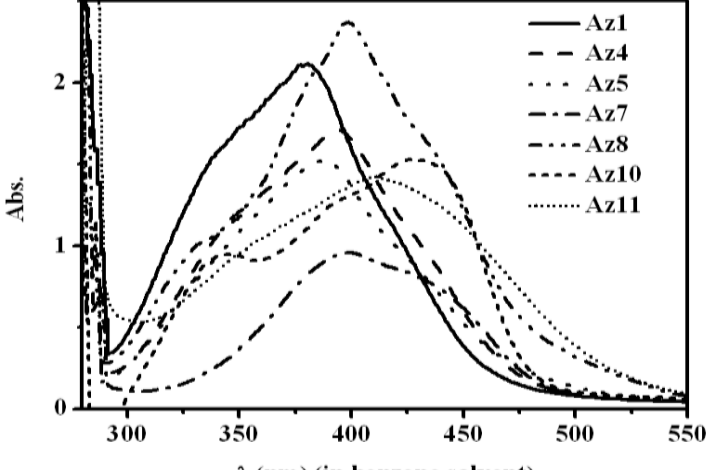

Figure 3. UV-Vis. spectra of investigated some azo dyes in the benzene solvent.

Figures 1, 2 and 3 show UV-Vis spectra of some investigated azo dyes in $\mathrm{CCl}_{4}$, 1,4-dioxane and benzene, respectively. The $\lambda_{\max }$ values of the Az4 and Az7 having o$\mathrm{Cl}$ and o-I substitutions were shifted to $400 \mathrm{~nm}$ in the case of $\mathrm{Cl}$ and $487 \mathrm{~nm}$ in the case of I due to the fact that their inductive electron withdrawing and resonance electron donating effects impose on opposing effects on each other. For the case of o-I substitution, the electron with drawing inductive effect is smaller than those of $\mathrm{Cl}$ atom due to the lower electronegativity of I atom. Therefore, the resonance effect is slightly higher and I act as a weak electron donating group. The $\lambda_{\max }$ value of Az1 is found to be almost equal to the $\lambda_{\max }$ values $\mathrm{Az} 2$. In that, $\mathrm{SO}_{3} \mathrm{H}$ substituent in meta position does not effect the $\lambda_{\max }$ values. According to $\lambda_{\max }$ values of $\mathrm{Az} 4$ (o-Cl substituent) and Az6 (p-Cl substituent), rezonans effect of $\mathrm{p}-\mathrm{Cl}$ is higher than inductive effect of o-Cl.

Azo dyes with an electron withdrawing group at one side of the molecule and an electron donating group at the other side are an example of the so-called push-pull molecules which are of interest in the field of non-linear optical molecules. The lowest energy electronic transitions correspond to $n-\pi^{*}$ electronic transition gives rise to increasing the push-pull character of molecules (Kim et al. 2000; Kim et al. 2001). As seen from the all of 
Table 2. UV-vis. spectra data in the various solvents of investigated azo dyes.

\begin{tabular}{|c|c|c|c|c|c|c|c|c|c|c|c|c|c|c|c|c|c|c|c|}
\hline \multirow{2}{*}{$\begin{array}{l}\text { Molecules/ } \\
\text { Solvents } \\
\text { AZ1 }\end{array}$} & \multicolumn{3}{|c|}{ DMSO } & \multicolumn{3}{|c|}{ DMF } & \multicolumn{3}{|c|}{ Ethanol } & \multicolumn{3}{|c|}{ THF } & \multicolumn{2}{|c|}{ Benzene } & \multicolumn{2}{|c|}{$\mathrm{CCl}_{4}$} & \multicolumn{3}{|c|}{ 1,4-Dioxane } \\
\hline & 268 & 384 & - & - & 388 & 426 & 253 & 388 & 414 & - & 381.5 & - & 380 & - & 377.5 & - & 257 & 378 & - \\
\hline AZ2 & 269 & 390 & - & - & 391 & 430 & 249 & 388 & - & - & 386 & - & 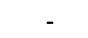 & - & - & - & 254 & 386.5 & - \\
\hline AZ3 & 267 & 406 & 444 & - & & 428 & 259 & 402 & 427 & - & 393 & 430 & - & - & - & - & - & - & 426 \\
\hline AZ4 & 268 & 398 & - & 268 & 398 & - & 254 & 400 & 430 & - & 394 & - & 393.5 & - & 392.5 & - & 256 & 393 & - \\
\hline AZ5 & 268 & 389 & - & - & 393.5 & 432 & 252 & 389 & 425 & - & 386.5 & - & 388 & - & 384 & - & 253 & 386 & - \\
\hline AZ6 & 265 & 392 & - & - & 396 & 431 & 253 & 396 & 422 & - & 387 & - & 386 & - & 384 & - & 255 & 385 & - \\
\hline AZ7 & 268 & 401 & - & 273 & - & 412 & 258 & 408 & - & - & 399 & - & 398 & 430 & 396 & - & 258 & 396 & - \\
\hline AZ8 & 263.5 & 403.5 & - & - & - & 440 & 253.5 & 401 & 432 & - & 398 & 439 & 399.5 & 440 & 395.5 & 437 & 255 & 399 & 435 \\
\hline AZ9 & 262 & 392.5 & 428.5 & - & - & 431 & 259.5 & 385.5 & 421 & 260.5 & 386 & 413 & 385 & 414 & 382 & 411 & 258.5 & 383.5 & 410 \\
\hline AZ10 & 272.5 & 402.5 & 448 & - & 404 & 442.5 & 254.5 & 398 & 438 & - & 397 & 425 & 397 & 427 & 396 & 430 & 254.5 & 397 & 425.5 \\
\hline AZ11 & - & 407 & - & - & 380.5 & 443.5 & 249 & 371 & 445 & - & 405 & - & - & 410 & 368 & 410.5 & - & - & 406.5 \\
\hline AZ12 & 273 & 408 & 428 & - & - & 435 & 246.5 & & 435.5 & - & 406 & 428 & - & 453.5 & 395 & 421 & 278 & 381.5 & - \\
\hline AZ13 & 261.5 & 389.5 & 421 & - & 400.5 & 432 & 253.5 & 386.5 & 424 & 255 & 385.5 & 418 & 393 & 421 & 390 & 435 & 253.5 & 384 & 412 \\
\hline AZ14 & - & 393 & 432 & - & - & 429 & 251 & - & 431 & - & - & 432 & 388 & 436 & 387 & 429 & 251 & 397 & 425 \\
\hline AZ15 & - & 391 & 424 & - & - & 410 & 247 & 391 & 411 & - & 385 & 418 & 383.5 & 419 & 382 & 414 & 249 & 383 & 417 \\
\hline AZ16 & 272 & 402 & 441 & - & - & 413 & - & 406 & - & & 398 & & 398 & 432 & 394.5 & 435 & 256 & 396 & 435 \\
\hline
\end{tabular}

the figures, we can say that this molecule is the highest non-linear optical molecule among the investigated azo dyes, since the optic intensity of third band $\left(n-\pi^{*}\right.$ electronic transition) in Az14 is comparatively larger than those of the second band ( $\pi-\pi^{*}$ electronic transition).

The data given in Table 1 and Figures 1-3 confirm that the position of wavelength depend on nature of substituents. In order to ascertain the relationships between shifts in maximum absorption band and substituents, the absorption wavelength values of second electronic transition band, which is $\pi-\pi^{*}$ electronic transition, seen from Table 1 were correlated by Hammett substituent constant as $\sigma$ constant (Hansch et al. 1991). The plot of $\lambda_{\max }$ versus $\sigma \mathrm{T}$ substituent constants for correlation in ethanol and DMSO solvents are shown in Figure 4 and 5, respectively. The three slopes of azo dyes were obtained in two solvents. For first solvent, linear correlation between total Hammett substituent constant $(\sigma)$ and $\lambda_{\max }$ of Az1-Az5-Az9-Az15-Az11, Az2-Az3-Az4$\mathrm{R}^{2}=0.78, \mathrm{R}^{2}=0.95$ and $\mathrm{R}^{2}=0.98$, respectively.

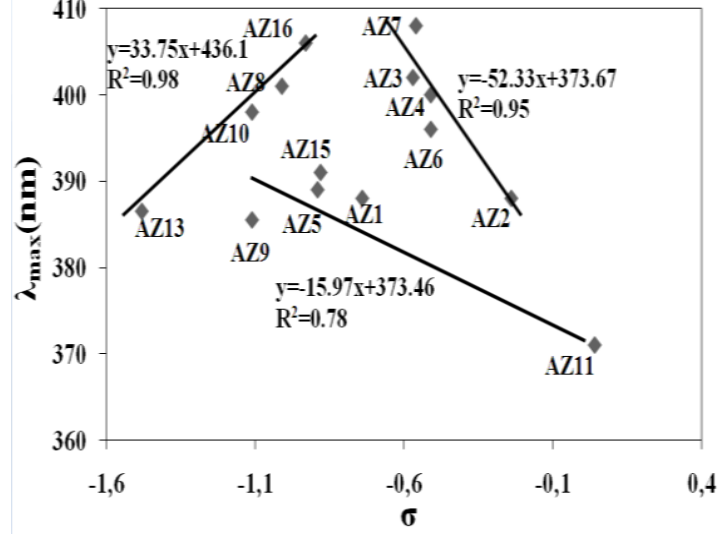

Figure 4. Plot of $\sigma$ vs $\lambda_{\max }$ in the ethanol solvent.

In Figure 5, we we have obtained $\mathrm{R}^{2}=0.948$ for $\mathrm{Az2}$ Az6-Az8-Az10-Az16, $\mathrm{R}^{2}=0.9546$ for Az4-Az7-Az9-Az11 Az13-Az14-Az3 and $\mathrm{R}^{2}=0.9905$ for Az1-Az5-Az12-Az15. The summation of Hammett substituent coefficients $(\sigma)$ are used to reproduce these slopes. Positive $\sigma$ value of the substituent gives rise to blue shift to $\lambda_{\max }$ values of molecules.

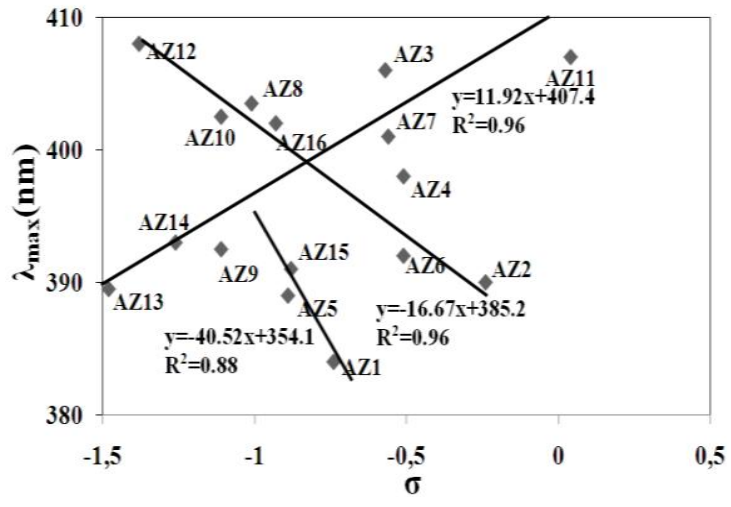

Figure 5. Plot of $\sigma$ vs $\lambda_{\max }$ in the DMSO solvent. 
On the contrary, if $\sigma$ value is negative, which have electron accepting substituent, it cause red shift to $\lambda_{\max }$ values of these molecules. The amount of shift in $\lambda_{\max }$ values and the magnitude of $\left(\lambda_{\max }\right) \mathrm{X}-\left(\lambda_{\max }\right) \mathrm{H}=\Delta \lambda_{\max }$ values are proportional to the electron donating ability and electron accepting ability of the substituent that depends on type and position of substituents. If the value of $\Delta \lambda_{\max }$ is small, there is only inductive effect electronic absorption spectrum. The presence of resonance effect increases the value of wavelength shift in absorption spectra. The highest $\Delta \lambda_{\max }$ is observed when both inductive and resonance effects come together. Investigated azo dyes show mostly bathochromic effect. When azo dyes have electron donor properties, it brings about bathochromic effect due to increasing conjugation and so photosensitization (Gülseven et al. 2009; Sıdır et al. 2009; Gülseven Sıdır et al. 2011ab).

On the other hand, azo dyes have the electron accepting properties which decrease conjugation and, thus, photosensitization of these molecules hardly depend to include both intermolecular and intra molecular hydrogen bonding. These molecules comes into being hypsochromic effect depending on propeties of solvents (Kim et al. 2000).

The substituents of benzene rings ( $A$ and $B$ rings) have a donor or acceptor properties, so, they exhibit antagonizing and/or additive effect on charge transfer interaction between the two moieties. The electron donating and electron accepting substituents on A benzene ring decrease the energy gap between the ground and excited states of the molecules. The scopes of $\lambda_{\max }$ as a function of the $\sigma$ (sum of Hammett substituent constant) give two straight lines with opposite slopes, indicating the applicability of the Hammett equation in the form (Issa et al. 1972):

$$
\left(\lambda_{\max }\right) \mathrm{x}=\left(\lambda_{\max }\right) \mathrm{H}+\rho(\sigma) \mathrm{x}
$$

As can be seen from Figure 4, the Az16, Az8, Az10 and Az13 dyes in ethanol solvents have electron accepting properties due to $\rho=33.75$. On the contrary, if $\rho$ have 52.33 and -15.97 , these molecules in ethanol solvents have electron donating properties. Since the $\rho$ value of Az13, Az14, Az7, Az3 and Az11 dyes in DMSO are 11.92, these molecules are electron acceptor. On the other hand, when $\rho$ is -16.67 and -40.52 , molecules in DMSO solvent are electron donor. Moreover, the change in $\rho$ 's sign indicates that the charge transfer between the two benzene rings for two directions.

We can say that in case of electron accepting azo dyes in direction of charge transfer is $B \rightarrow A$ with high interaction, while in case of electron donating azo dyes in direction of charge transfer is $\mathrm{A} \rightarrow \mathrm{B}$ with poor interaction due to the antagonization effects of the $\mathrm{OH}$ substituents of $B$ ring. Azo dyes on the same slopes have same electronic transition mechanism.

\section{Conclusion}

The absorption spectra of sixteen azo dyes having different substituents such as $\mathrm{OH}, \mathrm{SO}_{3} \mathrm{H}, \mathrm{Cl}, \mathrm{I}, \mathrm{NO}_{2}, \mathrm{C}_{2} \mathrm{H}_{5}$ and $\mathrm{OCH}_{3}$ have been evaluated by using UV-vis. spectra in various solvents. The effects of substituent on the electronic absorption spectra of azo dyes are investigated by correlations between absorption maximum wavelengths $(\mathrm{nm})$ and the Hammett substituent parameters. The charge transfer in these molecules was determined by these correlations.

\section{Acknowledgement}

We are grateful to Eskişehir Osmangazi University for the financial support to this work via the Research Project with the number of 200819015.

This work is dedicated to the memory of my Supervisor Cemil Öğretir, who died on January 19, 2011.

\section{References}

Aksu N (2007). Synthesis of monoazo compounds of some substitue anilin with benzene-1,3-diol and investigation of their tautomeric equilibrium, Msc Thesis, Anadolu University, Eskișehir, Turkey.

Bartkiewicz S, Matczyszyn K, Miniewicz A, Kajzar F (2001). High gain of light in photoconducting polymernematic liquid crystal hybrid structures. Opt Commun 187, 257-261.

Ermis E (2003). Bazı 2-substitue anilin ve benzen-1,3diol ile monoazo bileşiklerinin sentezlenmesi. Master Thesis, Anadolu University, Fen Bilimleri Enstitusu, Eskişehir, Turkey.

Gibson WM, Shannon PJ, Shao-Tang S, Swetlin BJ (1991). Surface-mediated alignment of nematic liquid crystals with polarized laser light. Nature 351, 49-50.

Giménez R, Millaruelo H, Piňol M, Serrano JL, Viňuales A, Rosenhauer R, Fischer T, Stumpe J (2005). Synthesis, thermal and optical properties of liquid crystalline terpolymers containing azobenzene and dye moieties. Polymer 46, 9230-9242.

Gregory P (1991). High-technology applications of organic colorants plenum, New York.

Gülseven Y, Taşal E, Sıdır İ, Güngor T, Berber H, Öğretir C (2009). Solvatochromic effect studies on the absorption spectra of 4-(2-ethylphenyl) diazenyl) benzene-1,3-diol and 2-((2-ethylphenyl) diazenyl) benzene-1,3,5-triol molecules. Int J Hydrogen Energ 34, 5255-5259.

Gülseven Sıdır Y, Sıdır İ, Berber H, Taşal E (2011a). UVspectral changes for some azo compounds in the presence of different solvents. J Mol Liq 162, 148-154.

Gülseven Sıdır Y, Sıdır İ, Tașal E, Ermiș E (2011b). Studies on the electronic absorption spectra of some monoazo derivatives. Spectrochim Acta Part A: Molec and Biomol Spectros 78, 640-647.

Hansch C, Leo A, Taft RW (1991). A Survey of Hammett Substituent Constants and Resonance and Field Parameters. Chem Rev 91, 165-195.

Issa RM, Assar SS, Dessouki HM (1992). Halochromic and electronic absorption spectral properties for some azoazomethine dyes. Egyptian J Chem 35, 321-334.

Kim JJ, Funabiki F, Muramatsu H, Shibato K, Kim SH, Shiozaki H, Hatmannd H, Matsui M (2000). Negative solovatochromism of azo dyes derived from (dialkylamino) thiazole dimers. Chem Commun 9, 753754.

Kim JJ, Funabiki F, Muramatsu H, Shibato K, Kim SH, Shiozaki H, Hatmannd H, Matsui M (2001). Synthesis, structure, and UV-VIS absorption spectra of azo dyes derived from (dialkylamino) thiazole dimers. J Chem Soc Perkin Trans 2, 379-387. 
Kobayashi S, Yokoyama H, Kamei H (1987). Substituent and solvent effects on electronic absorption spectra and thermal isomerization of push-pull-substituted cisazobenzenes. Chem Phy Let 138, 333-338.

Masoud MS, Ali AE, Shaker MA, Ghani MA (2005). Solvent and substituent effects on spectroscopical changes of some diazoaminobenzene derivatives. Spectrochim Acta Part A: Molec and Biomol Spec 61, 3102-3107.

Matsui M, Joglekar B, Ishigure Y, Shibito K, Maramatsu H, Maruto Y (1993). Synthesis of 3-Cyano-6-hydroxy5-[2-(perfluoroalkyl)phenylazo]-2-pyridones and their application for dye diffusion thermal transfer printing. Bull Chem Soc Jpn 66, 1790-1794.

Mijin DZ, Ušćumlić GS, Perišić-Janjić NU, Valentić NV (2006). Substituent and solvent effects on the UV/vis absorption spectra of 5-(3- and 4-substituted arylazo)4,6-dimethyl-3-cyano-2-pyridones. Chem Phy Let 418, 223-229.

Qian Y, Wang G, Xiao G, Lin B, Cui Y (2007). The firstorder molecular hyperpolarizability and thermal stability of charge-transfer azo diol and azo aldimine. Dyes and Pigments 75, 460-465.

Qui F, Cao Y, Xu H, Jiang Y, Zhou Y, Liu J (2007). Synthesis and properties of polymer containing azo-dye chromophores for nonlinear optical applications. Dyes and Pigments 75, 454-459.

Sıdır İ, Taşal E, Gülseven Y, Gungor T, Berber H, Oğretir C (2009). Studies on solvatochromic behavior of some monoazo derivatives using electronic absorption spectra. Int J Hydrogen Energy 34, 5267-5273.

So BK, Kim HJ, Lee SM, Song HH, Park JH (2006). Novel bent-shaped liquid crystalline compounds: IV. Dimesogenic compounds containing 2-hydroxy-1,3dioxypropylene and azobenzene mesogens. Dyes Pigments 70, 38-42.

Ušćumlić GS, Mijin DZ, Valentić NV, Vajs VV, Sušić BM (2004). Substituent and solvent effects on the UV/Vis absorption spectra of 5-(4-substituted arylazo)-6hydroxy-4-methyl-3-cyano-2-pyridones. Chem Phy Let 397, 148-153.

Valentic VN, Uscumlic SG, Radojkovic-Velickovic M (1999). Solvent effects on electronic absorption spectra of 3-N-(4-substituted phenyl)-5-carboxy uracils. J Serb Chem Soc 64, 149-154.

Ylldırım S (2007). Synthesis of monoazo compounds of some substitiue anilin with benzene-1,3,5-triol and investigation of their tautomeric equilibrium, Msc Thesis, Anadolu University, Eskişehir, Turkey. 